\title{
ANALISIS PENGHUJAHAN AL-RANIRI DALAM \\ KITAB FATHUL MUBIN ALA AL-MULHIDIN \\ TERHADAP GOLONGAN WUJUDIAH
}

\section{(An Analysis of al-Raniri's Arguments Against the Wujudiyyahin his Fathul-Mubin ala al-Mulhidin)}

\author{
Mohamad Nasrin Mohamad Nasir \\ mnasrin@ukm.edu.my \\ Institut Alam dan Tamadun Melayu, \\ Universiti Kebangsaan Malaysia.
}

Published on: 9 June 2020

To cite: Mohamad Nasrin Mohamad Nasir. (2020). Analisis Penghujahan al-Raniri dalam Kitab Fathul Mubin ala al-Mulhidin terhadap Golongan Wujudiah. Malay Literature, 33(1), 21-44.

\begin{abstract}
Abstrak
Artikel ini ${ }^{1}$ menganalisis secara kritis penghujahan yang diberikan oleh al-Raniri dalam kitab Fathul Mubin ala al-Mulhidin. Kitab Fathul Mubin ialah sebuah kitab yang telah dinukilkan oleh alRaniri setelah beliau kembali ke Ranir, Gujerat. Dalam konteks ini, al-Raniri telah menulis kitab ini setelah beliau tewas di tangan Syeikh Saiful Rijal di hadapan Sultanah Safiatuddin Shah yang merupakan Sultanah Acheh yang pertama selepas kemangkatan Sultan Iskandar Thani. Al-Raniri mengkritik pandangan wujudiah mulhidah berdasarkan pembacaannya terhadap beberapa buah kitab tulisan Syeikh Hamzah Fansuri dan Syeikh Shamsuddin Sumatrani. Kitab Fathul Mubin merupakan kitab yang sering dilupakan apabila membicarakan percanggahan tasawuf al-Raniri, dan yang sebelum daripadanya. Kebanyakan pengkaji melihat kitab al-Raniri yang lain dalam perdebatan ini. Pengkajian manuskrip Melayu pada hari ini telah menyedarkan sarjana akan kewujudan kitab ini dan sebagai hasilnya dapat dilihat pandangan al-Raniri tentang perdebatan tersebut yang lebih terperinci daripada kitabnya Jawahir al-Ulum
\end{abstract}


fi Kasfhul Ma'lum. Hasil penyelidikan menunjukkan bahawa ahli akademik perlu melihat kepada fakta yang sebenar melalui kaca mata yang baharu seperti yang ditemui dalam kitab Fathul Mubin. Oleh itu, memahaminya secara objektif adalah amat perlu agar persepsi yang terhasil berasaskan fakta dan penghujahan yang jelas.

Kata kunci: al-Raniri, Fathul Mubin, wujudiah, manuskrip Melayu, sejarah, sufi, tasawuf, Nusantara

\begin{abstract}
This paper will analyse critically the arguments given by al-Raniri in his Fathul Mubin ala al-Mulhidin. Al-Raniri wrote Fathul Mubin after returning to Ranir in Gujerat. From the context of the text it is clear that al-Raniri had written it after he lost in a debate with Shaykh Saiful Rijal before Sultanah afiatuddin Shah, who was then the Sultanah of Acheh after the death of Sultan Iskandar Thani (d.1646). Al-Raniri had criticized the views of the wujudiyyah whom he labelled mulhidah (heretical) based upon his readings of several books written by Shaykh Hamzah Fansuri and Shaykh Shamsuddin Sumatrani (d.1630). Fathul Mubin is one a text often forgotten when discussing the conflict between the Sufi teachings of al-Raniri and those before him. Researchers are tend to view his other works concerning this debate and conflict. Recent research into Malay manuscripts has alerted us to the existence of this text and as a result we are able to study the views of al-Raniri in more detail than in his other oftenviewed book, Jawahiral-Ulum fi Kasfhul Ma'lum. The findings of this research show us that we have to look back at the facts as stated in Fathul Mubin. Understanding the issue objectively enables us to see the facts and arguments in a clear and systematic light.
\end{abstract}

Keywords: al-Raniri, Fathul Mubin, wujudiyyah, Malay manuscripts, history, sufism, tasawwuf, Malay world

\title{
PENDAHULUAN
}

Nurruddin al-Raniri merupakan ulama yang telah menyumbangkan fikirannya dalam persuratan Melayu. Kitab-kitabnya dalam pelbagai bidang telah mengembangkan pemikiran orang Melayu dalam pelbagai aspek. Beliau dikenali sebagai ulama yang mengetuai suatu serangan dan perdebatan yang amat hebat di Acheh pada abad ke-17. Serangan yang dimaksudkan ialah perdebatan beliau dengan kumpulan yang dilabelkannya sebagai 
Wujudiah Mulhidah. Pada pandangan beliau, kumpulan ini mengikut ajaran Syeikh Hamzah Fansuri (awal abad ke-17 Masihi) ${ }^{2}$ dan Syeikh Shamsuddin Sumatrani (1630M).

Perdebatan dengan pihak wujudiah ini wajar dilihat semula secara objektif agar pandangan dan persepsi yang terhasil berasaskan fakta yang jelas.

\section{Sejarah dan Objektiviti Sejarah}

Perbincangan mengenai sejarah merupakan suatu yang agak sukar kerana sejarah itu merupakan tafsiran penyelidik. Bagaimana mahu melepaskannya daripada kerangka pentafsiran yang bersifat subjektif dan membawanya ke arah suatu pentafsiran yang bersifat objektif dan boleh diterima secara umum?

Hal ini merupakan suatu permasalahan falsafah yang masih diperdebatkan dalam kalangan ahli falsafah. Secara ringkasnya, perlu dijelaskan apakah objektif yang ingin dicari dan apakah maksudnya sama dengan apa-apa yang difahami oleh orang ramai atau tidak?

Secara umumnya, objektif itu disebut atau sering dianggap sebagai menandakan sesuatu yang bersifat universal dan boleh diterima oleh semua, kawan atau lawannya. Subjektif bermaksud memihak atau berat sebelah kepada sesuatu pandangan. Namun begitu, pandangan ini merupakan pandangan yang salah, walaupun popular namun ini salah.

Pada pandangan ahli falsafah objektif dan subjektif dalam bidang ilmu yang sering difahami seperti yang nyatakan di atas adalah tersilap kerana semua pandangan, tafsiran terhadap sejarah yang kemudiannya membentuk persepsi kita merupakan sesuatu yang subjektif. Menurut pandangan ahli falsafah sains yang terkenal, iaitu Karl Popper (1998) pandangan objektif dan subjektif yang diberikan di atas berdasarkan pandangan yang diberikan golongan positif yang sudahpun ditewaskan pada tahun 70-an.

Semua pandangan manusia merupakan pandangan yang bersifat subjektif kerana manusia itu dipengaruhi oleh persekitaran dan cara seseorang itu dibesarkan. Mana mungkin seseorang manusia itu membebaskan dirinya daripada dirinya sendiri.

Jika begitu adakah hal ini bermakna setiap pencarian yang cuba bersifat objektif itu sesuatu yang tidak mungkin?

To say that objective facts are now less influential in shaping opinion than appeals to emotion implies that there are such things as objective facts. In a truly post-truth environment, where the whole 
concept of truth had lost purchase, this claim would not be made or even understood.

(Blackburn, 2017)

Dalam pemikiran pascamoden, kebenaran bersifat tafsiran semata-mata. Tiada sesuatu yang objektif seperti kata Simon Blackburn (2017):

When post-modernists echoed Nietzsche's claim that "there are no facts, only interpretations," they were not belittling the process of interpretation. On the contrary, Nietzsche's aphorism highlights the importance of weighing up rival claims: it means that it takes experience, care, judgment and skill to fill our minds with sensible beliefs. Some such skills are unavoidable.

Nietzsche menunjukkan cara kita perlu sentiasa mempertimbangkan pandangan yang berbeza-beza pada satu-satu ketika. Pertimbangan inilah yang membentuk epistemologi kita.

It is sad that a childhood innocence that regards everyone as trustworthy has to be replaced, but it does. The process is called education. Its heart ought to be an appreciation of probability, of inference to the best explanation, of the intuitive use of statistical reasoning, or in short, epistemology.

(Blackburn, 2017)

Epistemologi mengandungi kaedah untuk menilai sesuatu. Penilaian ialah hasil kebarangkalian, inferens atau proses mengeluarkan kesimpulan dan kemampuan kita menggunakan data statistik. Semua ini menyumbang ke arah penerimaan seseorang terhadap penghujahan atau penyataan yang ditemuinya dalam dunia nyata. Situasi sebegitu akan mengelakkan kita menjadi seorang yang terlalu mudah percaya kepada apa-apa sahaja. Perkataan Inggerisnya ialah credulity, yang mempunyai makna mempunyai kecenderungan untuk mudah percaya kepada sesuatu sebagai benar atau betul (a tendency to be to ready to believe that something is real or true). Ertinya dalam sesuatu penyelidikan seseorang penyelidik itu hendaklah sentiasa mengawasi dirinya daripada dimanipulasi oleh kerangkanya tertentu sehingga boleh mengganggu objektiviti kajian tersebut (jeopardise the objectivity of the research). 
Secara kesimpulannya, bolehlah dikatakan bahawa apa-apa pernyataan yang dibuat tentang sejarah hanyalah hipotesis sehinggalah penyataan itu dibuktikan. Setiap kenyataan itu hanyalah hipotesis namun kenyataan sewajarnya diterima selagi tiada antitesisnya muncul. Dalam isu mengenai sejarah tasawuf didapati penemuan baharu dalam kajian manuskrip Melayu memerlukan penyelidik mengkaji ulang hipotesis mengenai kontroversi wujudiah di Acheh pada abad ke-17. Penemuan baharu yang dimaksudkan ialah penemuan kitab Fathul Mubin alal Mulhidin dan topik ini menjadi perbincangan dalam artikel ini.

\section{JUSTIFIKASI PEMILIHAN METOD PENILAIAN MENGGUNAKAN KAEDAH LOGIKO-DESKRIPTIF}

Kaedah ini dipilih kerana beberapa sebab yang akan dihujahkan di bawah. Yang pertama, tujuan penulisan makalah ini adalah untuk melihat objektiviti dan mengelakkan subjektiviti. Persoalannya, mengapakah hal ini penting telah dijelaskan di atas. Objektiviti sebagai kekuatan hujah dan bersifat logik, maka setiap yang dihujahkan seperti dalam tafsiran sejarah boleh dinilai oleh sesiapa saja, mengikut kaedah logik.

Tambahan pula menurut penulisan artikel ini al-Raniri tidaklah berhujah dengan Hamzah Fansuri dan Shamsuddin Sumatrani dari aspek spiritual atau mistikal (perjalanan rohani) beliau dan pandangan kasyaf beliau yang kesemuanya bersifat transenden yang semestinya tidak boleh dinilai dengan logik. Memandangkan al-Raniri menggunakan penghujahan berdasarkan penjelasan makna menurut disiplin bidang al-Quran dan al-hadis dan juga definisi berdasarkan kata-kata hukama terdahulu (seperti syeikh-syeikh sufi muktabar) maka membolehkan penilaian terhadap penghujahan beliau dibuat dengan menggunakan kaedah logika.

Seterusnya, dengan melihat dan menilai penghujahan sebegini maka penghujahannya boleh dilihat sebagai sesuatu yang objektif kerana objektiviti itu didefinisikan sebagai berdasarkan kekuatan penghujahan.

Disebabkan hujah-hujah inilah penulis menggunakan kaedah logikodeskriptif untuk menilai penghujahan al-Raniri. Ertinya penulis akan membawa hujah beliau (Raniri) terhadap Hamzah Fansuri dan Shamsuddin daripada dalam teks ini, iaitu teks kitab Fathul Mubin alal Mulhidin dengan menilai setiap tempat berlakunya dialektik dan polemik beliau terhadap kedua-duanya.

Diharapkan suatu kefahaman yang objektif, sistematik dan analitikal dicapai melalui proses yang berdasarkan teks ini sahaja, dan tidak berkait 
dengan teks-teks lain. Untuk mencapai kebenaran yang saksama semua teks dan kritikannya terhadap mereka berdua perlu dilihat dan dinilai, namun itu semua melampaui had artikel ini. Oleh itu, semua yang lain akan diabaikan dalam analisis ini. Keputusan atau kesimpulan yang dicapai pada penghujung artikel ini menghasilkan sesuatu yang benar berdasarkan teks yang dikaji ini sahaja.

Seterusnya pernyataan tentang makna sesebuah teks yang dibaca. Setiap teks yang dibaca perlulah dibaca secara sebaik mungkin dengan niat untuk mengetahui maknanya pada dirinya sendiri. Teks itu perlulah dilihat dengan niat untuk memahaminya terlebih dahulu dan bukannya digunakan untuk memberikan justifikasi terhadap pembacaan lain atau kepada suatu pentafsiran yang eksternal daripada teks.

Teks itu perlulah difahami atasnya sendiri, dan bukannya difahami dengan sesuatu yang eksternal padanya. Banyak berlaku salah faham kerana teks sering difahami menurut kefahaman si pembaca yang berkemungkinan tidak sampai untuk mencapai makna teks tersebut. Ketidaksampaian ini mungkin kerana kelemahan ilmu oleh pihak si pembaca atau kelemahan menguasai konsep yang diperlukan untuk memahami teks tersebut.

Jadi teks perlulah difahami seadanya. Teks bukanlah difahami dengan menggunakan sesuatu yang di luar daripadanya. Seperti berlaku perbincangan dan perdebatan yang panjang (yang masih berlarutan) dalam hal bagaimana sastera Melayu tradisional difahami oleh tokoh seperti R.O.Winstedt yang menggunakan kefahaman mengenai sastera Barat dan membaca sastera Melayu dengan kaca mata tersebut (Sweeney, 1980). Lantas dianggapnya sastera Melayu tradisional itu tidak kuat, lemah, tidak kompleks dan terdiri daripada suatu yang boleh ditinggalkan.

Perbincangan ini agak rumit, yang akan memanjangkan lagi artikel ini, dan juga menyebabkannya lari daripada topik perbincangan di sini. Secara ringkas perdebatan itu berkait dengan perkembangan dan perubahan sastera daripada lisan kepada penulisan dan bagaimana hal ini mempengaruhi pemikiran orang Melayu Nusantara (Sweeney, 1982). Perkembangan sastera di Barat dan di Nusantara banyak bezanya, dan tidak akan dibincangkan dalam artikel ini. Cukup sekadar untuk menyatakan bahawa inilah contoh apabila pemikiran eksternal pada teks dibawa untuk menilai teks yang ada di hadapan pembaca.

Oleh itu, teks perlu difahami seadanya ("A text has to be understood on its own terms" (Sweeney, 1990, p. 1006). Apabila sesebuah teks itu 
cuba difahami seadanya bukanlah bermakna usaha tersebut sesuatu yang mustahil. Oleh itu metode deskriptif membolehkan hal ini dilakukan dengan baik, yang menjelaskan teks seadanya dengan konteks yang menghasilkan teks tersebut.

\section{MENGENAI FATHUL MUBIN ALA AL-MULHIDIN}

Teks kitab Fathul Mubin ini pernah dikaji secara sepintas lalu oleh Ahmad Daudy dalam tesisnya ${ }^{3}$ mengenai al-Raniri dan juga dalam sebuah makalah yang diterbitkan pada tahun 1980-an. ${ }^{4}$ Menurut Ahmad Daudy (Daudy, 1987, p. 24) teks Fathul Mubin ini telah disenaraikan sebagai hasil tulisan al-Raniri oleh P. Voorhoeve (1955) dan Van Der Tuuk. Daudy menyemak teks Fathul Mubin ala al-Mulhidin yang dipunyai seorang yang tidak disebut namanya. Teks yang disemaknya hanyalah satu naskhah sahaja. Oleh itu, Daudy tidak mengetahui mengenai kewujudan naskhah yang lain (Daudy, 1987, p. 28).

Hasil daripada penyelidikan yang dimulakan oleh pihak Yayasan telah berjaya ditemui empat naskhah teks Fathul Mubin ala al-Mulhidin yang membolehkan penghasilan teks kritis.

\section{Deskripsi Naskhah yang Wujud di Malaysia}

Terdapat beberapa manuskrip yang bertajuk Fathul Mubin namun yang dimaksudkan di sini ialah Fathul Mubin Alal Mulhidin yang ditulis oleh Nuruddin al-Raniri. Manuskrip yang ditemui adalah seperti yang dihuraikan yang berikut:

\section{MSS 4661 - Tidak lengkap}

Tidak lengkap, tapi tulisannya besar memudahkan pembacaan.

Huruf "waw"nya tidak ke bawah tapi ekor "waw" itu ditarik ke atas seperti "qaf". Mengelirukan bagi sesiapa yang tidak biasa.

23 baris, 131 muka 1v.-66v

Kelihatan seperti teksnya disalin oleh dua orang yang berbeza kerana pada awal teks ditulis dengan menggunakan saiz fon yang kecil kemudiannya dari folio $40 \mathrm{v}$ tulisannya mula menggunakan fon dengan saiz yang lebih besar. Malangnya teks pada muka akhir tidak lengkap. Oleh itu tiada maklumat kolofon pada manuskrip ini. 


\section{Fath al-Mubin MSS 2148 - Lengkap}

Teks ini berakhir pada muka surat 217 dan 218 manuskrip.

Mengandungi 22 baris tulisan teks.

Mengandungi kolofon:

Wasallahu alihi kulli yawm Laylah ala man lana al-yawm al-qiyamah yashfa'

Dan yang empunya kitab Fathul Mubin ini Syeikh Abdul Wahhab ibn Marhum Tengku Hayat turun darul Islam Sultan Mansur Syah

Tutimma hadhihi nushkah al-munawwarah al-mansubah bi fathi al-mubin min ummuha lil Syeikh al-Alam al-Allamah al-Rashid 'ala tariqah al-Haqq al-mansubah lil qadhi walidha ahl al-khilafah Nuruddin ibn Muhammad ibn Ali ibn Hasani ibn Muhammad Hamid al-raniri al-Shafi'I na'maduhullah birahmatih wa askanahu mahjuhah hasanah.

Maka dimulai tersurat kitab ini pada shah rabiullawwal fi yawm althalatha fi waqt dhuaha fi bilad al-Acheh fi maqam atok pada ......alNabi Sallahualaihi wasallam seribu dua ratus enam puluh dua tahun pada tahun Zai, pada masa Raja Ala al-din Mansur Syah ibn Sultan Jawhar Alam Syah berdaulat khalillah fi al-alam.

Maka pada ketika tamat pada maqam Kampong Fendi/Pandai (?) pada daerah sebat barsah Kedah.

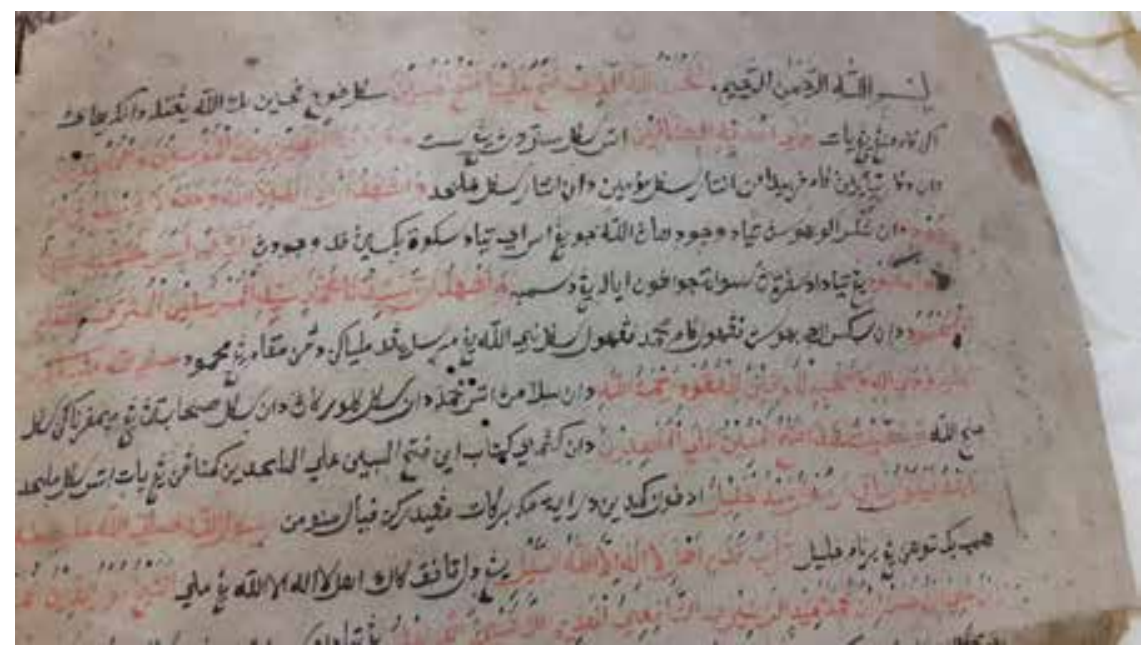

Rajah 1 Manuskrip MSS 3008, Pusat Manuskrip Melayu, Perpustakaan Negara Malaysia. 
3. Fathul Mubin MSS 3008 - Lengkap

Tidak jelas tulisannya, dan ada banyak tempat yang telah rosak dimakan air. MSS 3008 ini mengandungi beberapa tajuk yang lain juga selain Fathul Mubin. Deskripsinya pada muka surat 6, Tambahan Keempat agak mengelirukan kerana penyataan mengatakan bahawa Fathul Mubin ialah (D) dan daripada [ff.21v-31r.], manakala tajuk seterusnya, iaitu Audah alSabil ialah [31v.-115r.]. Setelah penelitian dilakukan, ternyata Audah al-Sabil adalah dari 31v hingga 31r, iaitu hanya satu folio 31. Teks Fathul Mubin merupakan yang terpanjang dan bermula daripada $32 \mathrm{v}$ hinggalah ke 230v dan bukannya $115 \mathrm{r}$ seperti yang tertulis dalam buku Tambahan Keempat.

4. Naskhah bernombor 17667 di Perpustakaan Dewan Bahasa dan Pustaka Manuskrip ini ada dalam simpanan Teuku Iskandar sehingga ke akhir

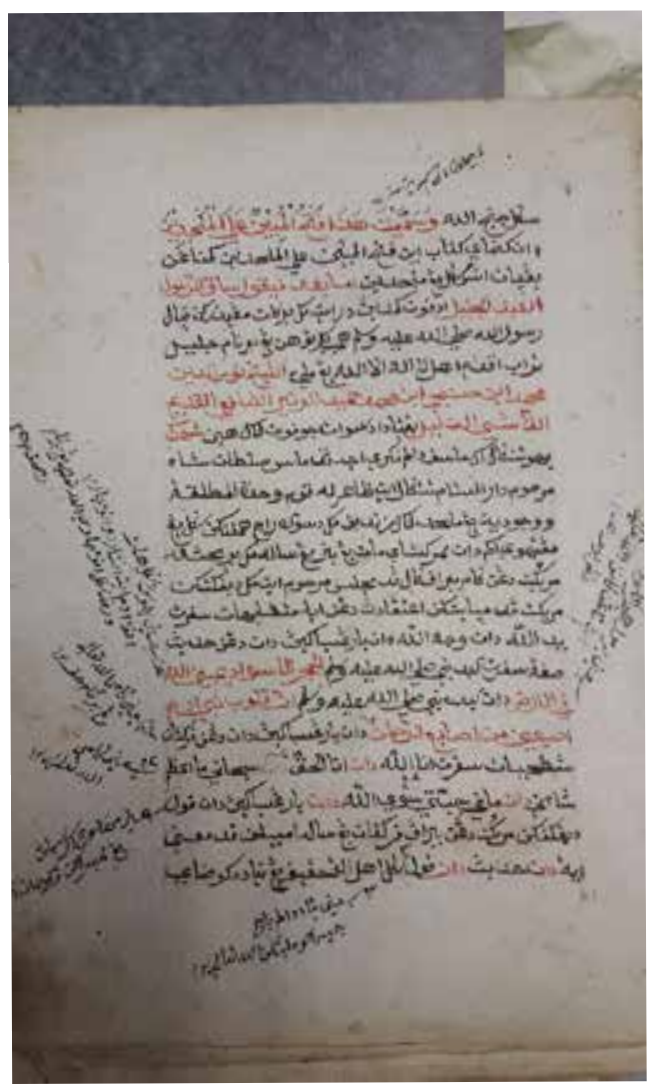

Rajah 2 Manuskrip MSS

3008, Pusat Manuskrip Melayu, Perpustakaan Negara Malaysia. 


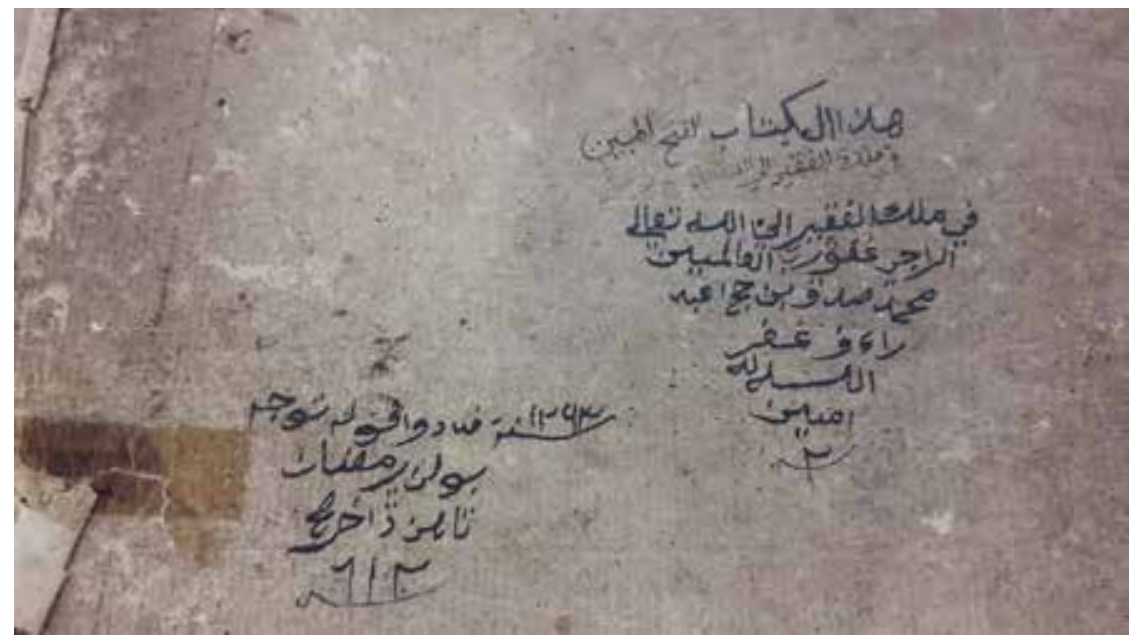

Rajah 3 Gambar Kolofon pada MSS 17667 di Perpustakaan.

hayatnya. Setelah kematiannya, manuskrip ini telah dipulangkan ke Perpustakaan DBP. Manuskrip inilah yang telah dirujuk oleh Voorhoeve dalam makalahnya, "Notes on some manuscripts in the library of the Dewan Bahasa dan Pustaka", (Voorhoeve, 1969).

Mengandungi 23 baris dan ditulis dengan tulisan yang boleh dibaca dengan baik. Tiada berlaku kerosakan daripada air atau kerosakan dakwat. Antara kesemua manuskrip yang ada, manuskrip inilah yang paling cantik ditulis. Walaupun begitu manuskrip ini tidak lengkap, dan tamat secara tibatiba pada folio 115 (v). Manuskrip ini telah dilihat oleh P.Voorhoeve sewaktu beliau melawat Malaysia pada bulan November tahun 1968 (Voorhoeve, 1969).

Secara umumnya, kesemua manuskrip yang ditemui ini tiada mempunyai provenance atau sejarah manuskrip. Yang ada hanyalah beberapa watermark dan juga kolofon yang menceritakan tentang siapa yang menghasilkan naskhah tersebut.

\section{ANALISIS TEKS}

Al-Attas dalam kajiannya terhadap kritikan al-Raniri tentang ajaran Hamzah Fansuri merujuk dua karya penulisan al-Raniri, iaitu al-Tibyan fi Ma'rifat al-Adyan dan juga Hujjat al-Siddiq $f i$ dhaf' al-Zindiq. Kedua-dua kitab 
ini menjadi asas kepada kefahaman al-Attas mengenai kritikan al-Raniri terhadap Hamzah Fansuri. ${ }^{5}$ Ahmad Daudy juga menggunakan kedua-dua kitab ini untuk menilai penghujahan al-Raniri tersebut. ${ }^{6}$ Walaupun begitu, beliaulah orang yang pertama menggunakan beberapa dapatan daripada Fathul Mubin dalam karyanya untuk membincangkan kritikan al-Raniri terhadap ajaran Hamzah Fansuri. Namun begitu, sehingga setakat ini, boleh disimpulkan bahawa tiada usaha yang kemas untuk memahami penghujahan al-Raniri seperti yang tertulis dalam kitab Fathul Mubin secara sistematik. Yang akan dilakukan dalam makalah ini adalah untuk melihat beberapa aspek penghujahan beliau yang menyebut secara terus nama orang yang ditujukannya, iaitu Hamzah Fansuri dan Syeikh Shamsuddin Sumatrani.

\section{Kritik terhadap Hamzah Fansuri dan Syeikh Shamsuddin Sumatrani yang Dinukilkan oleh al-Raniri dalam kitab Fathul Mubin alal Mulhidin}

Dalam kritikannya terhadap kedua-dua tokoh tersebut, al-Raniri jarang menyebut nama kedua-duanya. Sebaliknya, beliau mengikut langkah ulama pada masa lampau yang hanya menyebut nama kitab tanpa menyebut penulis yang dikritik. Walaupun begitu, beliau ada juga mengkritik Hamzah dengan menyebut namanya sebagai Fansuri.

Kitab yang dikarang Hamzah Fansuri:

\section{(1) Rubai}

(2) Al-Muntahī (al-Attas, 1969, pp.329-353; Abdul Hadi, 1984, pp. 89-111; Abdul Hadi 2001, pp.155-9)

(3) Zinah al-muwahhidīn (Doorenbos, 1933, pp. 176-204) (juga dikenali sebagai Syarāb al- 'Āsyiqīn)

Kitab yang dikarang Syeikh Shamsuddin al-Sumatrani:

(1) Kitab Khirqah atau Harakah

(2) Mir 'ātul Muhaqqiqīn (Van Nieuwenhuijze, 1945, pp. 298-360

(3) Kashf sìr al-Rubbubìyyah (Saghir Abdullah, 2002) ${ }^{7}$ 
Keenam-enam kitab ini dipetik al-Raniri dalam penghujahannya terhadap pandangan kedua-duanya. Penyemakan semula penghujahan oleh al-Raniri dapat dilaksanakan dengan adanya sebahagian besar kitab-kitab tersebut kecuali kitab Khirqah. Yang berikut disertakan pengkajian berserta perbandingan dengan apa-apa yang telah ditulis oleh si tuan (sahib) kitab masing-masing.

Pembahagian kepada 6 bahagian dilakukan seperti di bawah. Setiap penghujahan al-Raniri berasaskan petikan pada kitab musuhnya. Oleh itu, dalam analisis ini semakan semula terhadap kitab-kitab tersebut dengan melihat sama ada petikan itu tepat atau tidak. Kemudian akan dilihat penghujahan al-Raniri sama ada penghujahannya kuat ataupun bersifat kebetulan (accidental), iaitu mengikut keadaan (circumstantial).

\section{Yang Pertama:}

Dan lagi ditamsilkan mereka itu Haqq ta'ala umpamanya air sungai kembali kepada laut demikianlah alam itu kembali kepada Haqq ta'ala menjadi bersatu seperti kata empunya ruba'i:

Nyatakan ana al-Haqq jangan engkau takut Inilah ombak menjadi laut.

Maka jikalau ada seperti maksud mereka itu maka jadilah Haqq ta'ala itu berjisim dan keluar jisim daripadanya dan kembali pula kepadanya nauzubillah minha daripada beriktikad yang demikian itu.

Inilah iktikad kaum hukama' falasifah yang zindik katanya adalah alam alam itu keluar daripada wujud Allah seperti keluar keluar panas daripada matahari selama ada matahari adalah panas serta terang. Demikianlah ada alam serta Haqq ta'ala selamanya. ${ }^{9}$

\section{Yang kedua:}

Dan demikian lagi batillah dan ter..langlah kata yang empunya Ruba' I" "wahidkan hendak zahir dan batin dan inilah ilmu kesudahan main"

Wahidkan hendak fa'il dan ma'kul. Janganlah takhassuskan maqam tanzil, dan beberapa lagi perkataan yang kufur pada segala karangannya. 
Demikian lagi semata-mata kufur perkataan yang empunya Kitab Khirqah ${ }^{10}$ laknatullah alaihim dhallu wa sallu kathiran. ${ }^{11}$

\section{Yang Ketiga:}

Dengarlah kata yang empunya Muntahi,$^{12}$ pada syariat jua berbagaibagai rupa pada hakikatnya satu jua. Dan lagi pula katanya di dalam kitab itu, bahawa zat Allah dan sifat-Nya dan af'al-Nya dan athar-Nya itu sesungguhnya Kami bilang empat perkara tetapi pada hakikatnya esa jua. Tamsilnya seperti matahari dan cahayanya dan banyaknya sungguhpun kamu bilang dengan tiga perkara tetapi pada hakikatnya esa jua.

Kata yang empunya ${ }^{13}$ Mir'atul Muhaqqiqin ${ }^{14}$ bahawasanya Haqq ta'ala itu pada shariat Tuhan kami dan pada tarikat kekasih kami dan pada hakikat bersatu dengan kami dan pada makrifat bercampur dengan kami. ${ }^{15}$

\section{Yang Kelima:}

Kata yang empunya Ruba' ${ }^{16}$ "Ruh itu bangsa Rahman" dan lagi qawl katanya dalam kitab Muntahi ${ }^{17}$ kata orang Samudra, jika tiada membawak kufur bagimu sampaikan kufu..(?) dan kata empunya Mir'atul Muhaqqiqin, ${ }^{18}$ Bab yang kedua pada menyatakan nisbah makhluk dengan Haqq ta'ala. Dan lagi pula katanya dalam kitab Kashf sir al-Rubbubiyyah, ${ }^{19}$ "sekiyanya bagi rijalullah bahawa diketahuinya dan dikenalnya sebabnya yakni bangsanya dengan bansa zat Allah dan wujud-Nya".

Dan lagi qawl katanya dalam Kitab Khirqah ${ }^{20}$ dan semata-mata dengan kufur dan shirik dan segala ilmu zindik, "wallahu wabillah watallah insan itulah Allah". ${ }^{21}$

\section{Yang Keenam:}

Dan lagi katanya dalam Zinah al-Muwahhidin, ${ }^{22}$ adapun ahlil asyik tiada dapat ia membunyikan rahsia. Jikalau dikatanya perkataan yang bersalahan dengan syariat sekalipun maka tiadalah atasnya dosa seperti kata Maulana Rumi, "Man khoda am man khoda am", akulah Allah akulah Allah. Dan seperti kata Fansuri, Hallaj ana al-Haqq katanya itupun demikian jua, apabila kita ada asyik dan ma bak (tidak jelas) maka kita pun tiada dapat membunyikan rahsia kita. Maka kamipun kata barang kehendak kami maka tiada dapat dan tiada dosa. 
Kata yang empunya Mir'atul Muhaqqiqin ${ }^{23}$ adalah isyarat perkataan segala wali Allah seperti kata Abu Yazid, "Subhani ma a'zamu kulli shay'in qadir". ${ }^{24}$

Kata Fansuri Hallaj ana al-haqq kata ... (tidak jelas) Ana Allah. Sekelian itu mendalalatkan atas wujud dan bersatu zat Allah dan wujud-Nya dengan zat-Nya makhluk dan wujud-Nya. ${ }^{25}$

\section{Penghujahan al-Raniri}

Yang berikut merupakan penghujahan al-Raniri.

"Dan lagi katanya (HF) dalam Zinah al-Muwahhidin, adapun ahlil asyik tiada dapat ia membunyikan rahsia. Jikalau dikatanya perkataan yang bersalahan dengan syariat sekalipun maka tiadalah atasnya dosa seperti kata Maulana Rumi, "Man khoda am man khoda am", akulah Allah akulah Allah." ${ }^{26}$

"Hai saudaraku dengarlah perkataan zindik yang ahli mawjudah mutlak iaitu ahlul hulul dan ittihad adalah mereka itu mengambil hujjah dan dalil pada menyatakan iktikadnya yang sesat dengan ayat mutashabihat dan dengan hadis sifat dan dengan perkataan shattahiyyat.

Maka barang siapa mengambil hujjah dan dalil dengan tiga perkara yang tersebut itu pada menyatakan iktikadnya bahawa Haqq ta'ala itu sewujud dan bersatu dengan makhluk maka jadilah ia kafir murtad yang zindik pada sekelian mazhab agama Islam.”

\section{Kata-kata Hamzah Fansuri yang sebenar:}

Yang berikut merupakan kata-kata Hamzah Fansuri.

"Adapun orang berahi yang tiada dapat menaruh rahsianya -seperti kata Mawlana Rum:

Man khuda am! Man khuda am! Man khuda am! Ya'ni: aku Allah! Aku Allah! Aku Allah!

Katanya itu kata mabok, bukan hawa nafsunya. Dan seperti kata Syeikh Mansur [al-Hallaj] mengatakan Ana al-Haqq ! Itu pun [demikian]. Jangan kita menurut katanya [kerana kita tiada maghlibul hal]. Tetapi jika berani dan mabuk - tiada tertaruh rahasia kita lagibarang yang dikatakan tiada berdosa. Fa ifham!"27 
Kelihatan penghujahan Hamzah bukanlah seperti yang dikatakan alRaniri sebaliknya beliau menjelaskan mengenai mereka yang maghlibul hal. Menarik sekali, al-Raniri sendiri menggunakan hujah yang sama dalam mengiyakan kata-kata al-Hallaj. Dalam penjelasannya mengenai Shattahiyyat yang terkandung di dalam kitab Fathul Mubin, al-Raniri berkata:

"Adapun sebab terlanjur lisan mereka itu dengan tiada diiktikadkan
yang demikian seperti terlanjur lisan dengan perkataan yang jahat-
jahat keji daripada orang yang mabuk dan mengikuti dengan lalinya.
Dan orang yang latah dan nyanyuk dan gila dan barang sebagainya.
Maka apabila ia siuman maka sembuhlah daripada yang demikian.
Maka ditanya orang daripada hal yang demikian maka sahutnya
sekali-kali tiada aku berkata-kata yang demikian itu dengan ikhtiarku
Dikata aku tiada sedar dan ingat daripada barang yang keluar daripada
lisan ku. Dan demikian lagi adalah segala wali Allah senantiasa
di dalam zikir menyebut Allah, Allah dan Haq, Haqq dan Hu, Hu
hingga hasillah akan mereka itu muraqabah dan ma aniyyah dan
mukashafah dan mushahadah hingga karam dan dan ghayblah ia
daripada penglihatan dirinya akan barang yang lain daripada-Nya.

Al-Raniri menyambung mengenai kata-kata Husayn ibn Mansur alHallaj,

"Dan demikian lagi yang mengatakan "Ana Allah", itu Allah, dan yang mengatakan "Ana al-Haqq" itu Haqq ta'ala jua. Dan yang mengatakan Subhani ma a'zamu sha'ni itu Haqq ta'ala yang Maha suci lagi maha besar kelakuannya. Dan bukannya yang mengatakan yang demikian itu hamba yang hadis lagi hina bahwa sekali-kali tiada layak dan tiada patut mengatakan akan dirinya yang demikian jikalau keluar daripada lisan sekalipun...

Beliau menambah penjelasan beliau dengan sebuah hadis Nabi SAW yang menjelaskan mengenai kata-kata Umar. Menurut al-Raniri Umar juga pernah berkata seperti Husayn ibn Mansur al-Hallaj.

Maka adalah ia seperti sabda Nabi sallahu alaihi wasallam, "Innallah yantiqu ala lisan umar", yakni bahawasanya Haqq ta'ala itu berkatakata atas lisan Umar yakni adalah Haqq ta'ala zuhur dan tajalli atas lisan Umar dengan perkataan atas yang sebenar-benarnya. 
Maka pada pandangan al-Raniri tiadalah salah keterlanjuran kata-kata wali Allah apabila mabuknya itu menguasainya:

Jikalau ada terkadang terlanjur lisannya setengah wali Allah sekalipun tiada dengan ikhtiyarnya dan tiada dengan tiada diiktikadnya yang demikian. Dikata adalah iktikad yang demikian kufur jua sanya dari kerana itulah Syeikh Abu Yazid tatkala pada hal ghalabah mabuknya dengan tiada ikhtiayarnya. Maka terlanjur lisannya mengatakan "Subhani ma a'zamu sha'ni" maka tatkala siuman dan sembuhlah ia daripada hal mabuknya itu."

Wali Allah yang dimaksudkan al-Raniri ialah Syeikh Abu Yazid alBistami yang terkenal dengan shattahiyyat:

Dari kerana inilah kata setengah arif pada mentakwilkan kata Syeikh Abu Yazid, "Rabbi ... (tidak jelas) ala lisan 'abdihi", yakni Tuhan mengucap tasbih akan diri-Nya atas lisan hamba-Nya. Yakni bukan Abu Yazid yang mengatakan dirinya yang demikian" ${ }^{28}$

Al-Raniri menambah penghujahannya dengan merujuk sebuah kitab yang tidak lagi diterbitkan, iaitu kitab Zawarif al-lata 'if fi Sharf al-Awarif al-ma'arif. ${ }^{29}$ Kitab ini mensyarahkan teks Sufi yang terkenal, iaitu $\mathrm{Al}$ - 'Awarif al-Ma'arif tulisan Abu Hafs Umar Suhrawardi.

Kata yang empunya Zawariq pada sharah 'Awarif bahawa kata Syeikh Abu Yazid yang demikian itu jua diperlakukan Allah atas lisan-Nya perkataan daripada diri-Nya jua. Iaitu tatkala karamlah hati Syeikh Abu Yazid dan ghalabah mahabbah Allah atasnya. Hingga fanalah ia daripada segala masuk (tidak jelas) Allah. Maka dilihatnya pada hatinya Nur Haqq ta'ala. Dan demikian lagi kata Syeikh Husayn ibnu Mansur Hallaj, “Ana al-Haqq” tatkala ghalabah mahabbah Haqq ta'ala atas hatinya hingga dimabukan akan Dia. Maka fanalah ia daripada penglihat dirinya lalu terlanjur lisannya dengan mengatakan "Ana alHaqq" tiada dengan ikhtiyarnya. Dan tiada ia maksudkan dirinya. ${ }^{30}$

\section{PERBINCANGAN}

Jelaslah persamaan penjelasan al-Raniri dengan Hamzah Fansuri dalam hal maghlibul hal. Oleh itu tidak adil sekiranya dituduh Hamzah mengatakan 
sesuatu yang tidak dikatakannya. Ajaran Hamzah Fansuri tidaklah menganjurkan hulul dan ittihad, iaitu zat Allah dan zat insan itu bersatu, namun shattahiyyat itu ialah mabuk dalam berzikir dan menjadikan mereka maghlibul hal, sehinggakan tiadalah mereka itu sedar akan diri mereka sendiri.

Dapat dilihat bahawa al-Raniri sering menggunakan metode falasi orangorang (straw-man fallacy) untuk menegakkan hujah beliau terhadap hujah wujudiah. Straw-man fallacy ialah falasi terhadap hujah lawan yang disebut dengan cara salah, tersasar, ditokok-tambah atau tidak disebut dengan tepat. Hal ini dilakukan untuk memudahkan beliau menolak hujah lawan tersebut.

Seperti yang telah ditunjukkan di atas, penghujahan Hamzah Fansuri tidak dijelaskan dengan baik, malah ditokok tambah dengan mengatakan Fansuri bermaksud atau berimplikasi sedemikian padahal apabila dikesan hujah Fansuri dalam tulisan beliau sendiri, didapati maksud Fansuri berbeza dengan apa-apa yang diimplikasikan oleh al-Raniri.

Kemungkinan hujah ini diterima oleh Sultan Iskandar Thani, namun tidak dapat diterima dengan baik oleh Sultanah Tajul Alam Safiyatuddin Shah. Pihak Ulubalang yang membuat keputusan menolak penghujahan seperti itu dan memberikan kemenangan kepada Saifurrijal. Pada akhir kitab, al-Raniri memohon agar kitab ajaran wujudiah dibakar dan tidak dibenarkan dibaca. Beliau juga meminta agar mereka yang mengikut "kesesatan" wujudiah dihukum bunuh jika mereka enggan bertaubat. Lebih menarik lagi beliau mengatakan bahawa kitab Fathul Mubin ini ditulis olehnya:

Kiriman untuk saudaraku yang di Pulau Acheh, di negeri Kedah, dan yang di pulau Banten, dan yang di pulau Makasar, dan yang di negeri Johor, dan yang di begeri Pahang, dan yang di negeri Petani, dan yang di negeri Singora dan kepada segala daerah negeri yang di bawah angin."

Petikan ini menunjukkan betapa berpengaruhnya ajaran wujudiah sehingga meliputi banyak tempat dan daerah. Apakah wujudiah ini atau ajaran wahdatul wujud ini bersamaan dengan apa-apa yang diajarkan di madrasah Hijjaz dan semenanjung Jaziratul Arab dan Persia? Hal itu tidaklah dapat dipastikan.

Namun begitu, pandangan Syeikh Abdul Ra'uf Singkel (m.1680-an) menarik untuk dilihat kerana beliau berada di Acheh selepas kasus al-Raniri. Menurut beliau: 
“... bahawa ketika saya sampai di Aceh, ada seseorang datang kepada saya berkali-kali, saya melihat ia berbicara tentang wahdatul wujud yang berbeda dengan apa yang telah diajarkan syekh saya Ahmad ibn Muhammad al-Madani al-Ansari as-Samadani yang dikenal dengan al-Qusyasyi dan khalifah Alam yang luas pemahamannya, iaitu syekh kami Burhanuddin Mula Ibrahim bin Hasan al-Kurani semoga Allah merahmati keduanya."

(Fathurrahman, 2008, pp. 123-4)

Jika pandangan ini benar, ini menandakan bahawa ajaran tasawuf Melayu itu agak unik jika dibandingkan dengan apa-apa yang diajarkan di Mekah dan tempat-tempat lain. Berlakunya perubahan pendekatan apabila sampai di Acheh merupakan suatu fenomena yang menarik kerana keadaan ini menandakan penyesuaian telah berlaku daripada ajaran asal wahdatul wujud.

Kelihatannya al-Raniri menekankan aspek tanzih manakala dituduhnya Hamzah Fansuri dan Shamsuddin sebagai terlalu menekankan tasbih sehingga melupakan aspek tanzih. Terlalu menekankan aspek tasbih mengakibatkan pengikut mereka terkeliru sehingga menyangkakan diri mereka ialah Allah melalui penyataan "Ana Allah" dan "Ana al-Haqq". Penyataan ini merupakan hujah al-Raniri yang paling jelas terhadap tasawuf kedua-dua tokoh tersebut.

Beliau membawa contoh-contoh daripada tulisan mereka berdua tanpa konteks untuk membuktikan aspek ini. Malangnya penghujahan al-Raniri itu tidak bersifat objektif, sebaliknya bersifat subjektif. Untuk menegakkan penghujahannya, beliau hanya melihat aspek yang boleh digunakan daripada penulisan tokoh tersebut untuk menguatkan hujahnya. Padahal sebagai seorang yang adil dalam menilai hujah, sesebuah hujah itu perlu dilihat dengan teliti berserta dengan konteksnya. Tidak memahami konteks mengakibatkan penghujahan jatuh dalam falasi argumentum ad hominem dan falasi yang lain.

\section{Persoalan Wahdatul Wujud dan Hubungannya dalam Merungkai Kesalafahaman mengenai Isu}

Pada pandangan Hamzah Fansuri, wujud itu hanyalah Allah yang lain merupakan sirful wujud atau kelihatan seperti wujud tapi sebenarnya tidak wujud dengan hakiki. ${ }^{31}$ Kata Hamzah Fansuri: 
Tuhan kita itu yang bernama .Aliyy

Dengan Sekalian Sifat-Nya senantiasa bāq $\overline{1}$

.Alā jamīi.l-ālamīn thārNya jadi

Daripada situ jihāt-sebab inilah khālī

Chahaya thār-Nya tiadakan padam

Memberikan wujūd pada sekalian .ālam

Menjadikan makhlūq siang dan malam

Ilā [abadi].l-ābād tiada.kan karam

(al-Attas, 1970, p. 236)

Betapa popularnya pengajaran wujudiah pada zaman tersebut disebut al-Raniri sendiri dalam teks ini. Manusia Muslim pada zaman tersebut amat mengharapkan mencapai jalan tahqiq untuk mencapai pertemuannya dengan Allah. Betapa berbezanya pada hari ini apabila doa dan pengamalan dilakukan untuk mengejar syurga Allah dan bukannya untuk Allah sematamata. Keyakinan manusia Muslim pada zaman tersebut mendorong mereka mencari Allah di mana-mana. Malangnya kerana keterhadan penguasaan bahasa mereka menjadikan mereka tidak dapat membaca karya asli yang ada dalam bahasa Arab dan Farsi. Hal ini disebut oleh Syeikh Shamsuddin sendiri dalam Haqqul Yaqin:

Bahawasanya tatkala kulihat terbanyak daripada orang yang muliamulia daripada segala saudaraku yang salih Yang hasrat mereka itu daripada sungguh-sungguh pada mengikut tapak segala arif Kerana tiada ada mereka itu tahu akan bahasa Arab dan akan bahasa Farisi Tetapi tiada diketahui mereka itu hanya bahasa orang Pasai Kiranya daripada tenatnya mereka itu dengan sebaik-baik balas Dan dilanjutkan Allah ta'ala kiranya mereka itu dengan dia hingga hari yang kemenangan dengan beroleh liqa' Allah Maka berkehendak Aku mencari barang yang dinyatakannya ia ialah penglihat segala wali Allah Dikelubungi Allah ta'ala kiranya mereka itu dengan segala keredhaan-Nya Maka kuhimpunkan daripada erti segala kalimat pada 'ilmu Haqiqah Ibaratnya yang menunjukkan kepada yang seni-seni Serta maka kita elakkan dengan kata yang diketahui mereka itu Dan kuhimpunkan dengan bahasa yang ingat mereka itu Supaya dapat diberikan mereka itu dengan kata ibarat Dan supaya dapat dinyatakan mereka itu dengan kenyataan isharat (dan kunyatakan padanya jalan segala salik dan kuidhafkan kepadanya jalan segala yang berjalan kepada Allah ta'ala pada hal naik ia kepada segala pangkat mujid yang arif pada hal samar isharah kepada segala kesempurnanaanya yang 
kamil mukammil) Supaya mudah pada hati segala yang menuntut dia menguraikan segala simpulannya"

Dan lagi kata-katanya yang berkesan apabila dikatanya,

Maka bahawasanya talib yang sadiq barang siapa diperbaikinya ibadatnya akan Tuhan nya Dan sejahtera I'tiqadnya yang dianugerahkannya akan memandang Tuhannya Maka bahawasanya yang terlebih besar daripada segala jalan yang terlebih tingginya, iaitu jalan kepada Allah ta'ala.

Hal ini juga terbukti apabila al-Raniri, pada pengakhiran kitab Fathul Mubin, menyebutkan betapa beliau berharap tulisannya ini mencapai ke beberapa tempat di mana manusia Muslim berada, antaranya disebut:

Inilah haluwatku kiriman ${ }^{32}$ kepada segala saudaraku yang dipulau Acheh dan yang dinegeri Kedah dan yang di Pulau Bintan dan yang di Pulau Mengkasar dan yang di negeri Johor dan yang dinegeri Pahang dan negeri Fatani dan yang di negeri Sengora dan pada daerah negeri yang dibawah Angin.. ${ }^{33}$

Ertinya, jika dibaca dengan kaca mata sosiologi, betapa bersemaraknya pencarian Tuhan itu dilakukan oleh manusia Muslim pada zaman tersebut. Di sini ditemui satu lagi kaedah pengkajian manuskrip, yang boleh dilakukan oleh penyelidik, iaitu pencarian fakta sosiologi dengan berasaskan tujuan penulisan kitab.

\section{KESIMPULAN}

Kemungkinan juga al-Raniri tidaklah terlalu salah dalam menentang pengikut wujudiah yang tiada dipimpin lagi oleh Syeikh Hamzah maupun Syeikh Shamsuddin kerana kedua-duanya telah meninggal apabila al-Raniri mendepani wujudiah pada tahun 1630-an. Menarik sekali melihat kepada kata-kata Syeikh Abdul Ra'uf Singkel dalam kitabnya Tanbih al-Māshī. Syeikh Abdul Ra'uf yang memegang jawatan Syeikhul Islam pada tahun 1662, selepas kematian Sayf al-Rijal (Ito, 1978).

Kata-kata beliau pada permulaan kitab Tanbih al-Māshī 'alā Tarīqa alQushāshī ini menandakan ada dalam kalangan mereka yang salah memahami 
wahdatul wujud dan tidak bertepatan dengan yang diajarkan oleh kedua-dua Shaikh Abdul Rauf tersebut.

Apakah makna wahdatul wujud yang dikatakan berbeda itu salah dan membawa kearah kesesatan? Atau apakah berbeda disini bermaksud hanya berbeda manhaj dan bukannya membawa ke arah kesesatan. Mungkin ini boleh disiasat lagi dalam makalah yang lain. Begitu juga dengan ajaran wahdatul wujud di nusantara. Berbeza dengan ajaran di negara Arab dan Persia, wahdatul wujud itu diajar dengan menggunakan teks induk seperti Fusus al-Hikam dan pelbagai syarahnya, di Nusantara pengajaran wahdatul wujud itu hanya menekankan martabat tujuh dan perhubungan antara Tuhan dan manusia secara tidak sistematik. Penulisan kitab adalah sesuatu yang menyahut kehendak rakyat terbanyak dalam sesebuah masyarakat Islam.

\section{NOTA}

1. Sebahagian daripada makalah ini telah dibentangkan di "The 2nd International Conference on Religion \& Society" yang diadakan di Universiti Malaysia Sabah pada 22 Ogos 2017 yang lalu. Untuk tujuan penerbitan dalam jurnal ia telah dikembangkan dan ditambah agar ia berbeza dari prosiding yang telah terbit.

2. Untuk mendapat suatu pandangan ringkas mengenai biografi of Ḥamzah Fanşūrī, lihat S. M. N. al-Attas, The Mysticism of Hamzah Fanşūrī (Kuala Lumpur: University Malaya Press, 1970) 3-30. Untuk pandangan yang ringkas dan padat lihat $\mathrm{Hj}$ Muhammad Bukhari Lubis, The Ocean of Unity, Waĥdat al-Wujūd in Persian, Turkish and Malay Poetry (Kuala Lumpur: Dewan Bahasa dan Pustaka, reed. 1994), pp. 274-81, G. W. J. Drewes and L. F. Brakel (The Poems of Hamzah Fansuri [Dordrecht: Foris KITLV, Bibliotheca Indonesia 26, 1986]) Untuk rumusan dan pandangan Braginsky, lihat juga bukunya The Heritage of Traditional Malay Literature: A Historical Survey of Genres, Writings and Literary Views (Leiden: KITLV Press, 2004), 744, n. 13.

3. Ahmad Daudy. (2002). Allah dan Manusia dalam Konsepsi Syekh Nuruddin arRaniry. Jakarta: Penerbit Bulan Bintang.

4. Ahmad Daudy. (1987). Tinjauan atas 'al-Fath al-Mubin 'Ala al-Mulhidin karya Syaikh Nuruddin ar-Raniri. Ahmad Rfa'I Hasan (Ed..), Warisan Intelektual Islam Indonesia, Telaah atas Karya-Karya Klasik. Bandung: Penerbit Mizan, 19-35.

5. Al-Attas, Raniri and the Wujudiah of Acheh.

6. Ahmad Daudy (2002). Allah dan Manusia dalam konsepsi Syekh Nuruddin arRaniry. Jakarta: Bulan Bintang, 189-222.

7. Kitab ini manuskrip bernombor MSS 15 di Pusat Manuskrip Melayu, Perpustakaan Negara Malaysia. Versi ruminya boleh dilihat di W.Saghir W.Abdullah. (2002). AlMa'rifah 1, Kuala Lumpur: Khazanah Fathaniyyah.

8. Muka surat 9 pada naskhah rumi MSS A (DBP).

9. Hamzah Fansuri. 
10. Syeikh Shamsuddin al-Sumatrani.

11. Muka surat 91 MSS A (DBP).

12. Syeikh Hamzah Fansuri.

13. Akhir muka surat 169 (180 manuskrip).

14. Syeikh Shamsuddin al-Sumatrani.

15. Muka surat 170 MSS A (DBP).

16. Ruba'I merupakan sekumpulan puisi tulisan Syeikh Hamzah Fansuri.

17. Al-Muntahi merupakan sebuah karangan tulisan Syeikh Hamzah Fansuri.

19. Merupakan sebuah karangan tulisan Syeikh Shamsuddin al-Sumatrani.

19. Merupakan sebuah karangan tulisan Syeikh Shamsuddin al-Sumatrani.

20. Merupakan sebuah karangan tulisan Syeikh Shamsuddin al-Sumatrani.

21. Muka surat 179 (190) MSS A (DBP).

22. Tulisan Syeikh Hamzah Fansuri.

23. Tulisan Syeikh Shamsuddin Sumatrani.

24. Kata-kata sebenar ialah, "subhani ma a'zamu sha'ni” lihat Risalah Qushayriyyah, Kashful Mahjub, Kitab al-Lum'a yang kesemuanya merupakan kitab yang ditulis pada peringkat awal perkembangan tasawuf.

25. Muka surat 204 (215) MSS A (DBP).

26. Mukasurat 204 (215) MSS A (DBP).

27. al-Attas (1970), muka surat 327).

28. Fathul Mubin, folio 100v-104v.

29. Kitab ini dijumpai di Perpustakaan Universiti King Saud di Riyadh yang dicatatkan di bahagian hashiyyah manuskrip 'Awarif.

30. Fathul Mubin, folio 104v.

31. Sila lihat perbincangannya di Mohamad Nasrin Nasir. Persian Influences in the Teachings of Ḥamzah Fanșūrì”. Imtiyaz Yusuf (Ed.) Proceedings of the International Conference on Measuring the Effects of Iranian Mysticism upon Southeast Asian Mysticism. Bangkok: Iranian Cultural Center, 2004, ms. 7. Makalah ini boleh dilihat di https://ukm.academia.edu/Mohamad Nasrin Nasir.

32. Menandakan kitab ini telah disiapkan oleh al-Raniri hanya selepas beliau meninggalkan Acheh.

33. Daripada manuskrip MSS 2148 folio akhir.

\section{RUJUKAN}

Abdul Hadi W.M. dan L.K. Ara (Eds.). (1984). Hamzah Fansuri Penyair Sufi Aceh. Aceh: LOTKALA

Abdul Hadi W.M. (2001). Tasawuf yang tertindas: Kajian Hermeneutik terhadap Karya-karya Hamzah Fansuri. Jakarta:Penerbit Paramadina.

Ahmad Daudy. (2002). Allah dan Manusia dalam Konsepsi Syekh Nuruddin arRaniry. Jakarta: Penerbit Bulan Bintang.

Ahmad Daudy. (1987). Tinjauan atas 'al-Fath al-Mubin 'Ala al-Mulhidin karya Syaikh Nuruddin ar-Raniri. Ahmad Rfa'I Hasan (Ed.), Warisan Intelektual 
Islam Indonesia, Telaah atas Karya-Karya Klasik. Bandung: Penerbit Mizan, ms.19-35.

al-Attas. (1970). The Mysticism of Hamzah Fanşūrī. Kuala Lumpur: University Malaya Press.

Blackburn, Simon. ( June, 2017). There is nothing new about Post-Truth Politics, We've always had to fight for facts - but it's particularly important right now. Prospect Magazine, 20th June 2017.

Braginsky, Vladimir. (2004) The Heritage of Traditional Malay Literature: A Historical Survey of Genres, Writings and Literary Views. Leiden: KITLV Press.

Doorenbos, J. (1933). De geschriften van Hamzah Pansoeri: uitgegeven en toegelight. Leiden: Batteljee \& Terpstra.

Drewes, G.W.J. and Brakel, L. F. (1986). The Poems of Hamzah Fansuri. Dordrecht: Foris KITLV, Bibliotheca Indonesia 26.

Fath al-Mubin MSS 2148, Pusat Manuskrip Melayu, Perpustakaan Negara Malaysia.

Fathul Mubin MSS3008, Pusat Manuskrip Melayu, Perpustakaan Negara Malaysia.

Fathul Mubin, no. 17667 di Perpustakaan Dewan Bahasa dan Pustaka, DBP.

Fathurrahman, Oman. (2008). Tarekat Syattariyah di Minangkabau. Jakarta: Prenada Media Group.

Hj Muhammad Bukhari Lubis. (1994). The Ocean of Unity, Wahdat al-Wujūd in Persian, Turkish and Malay Poetry. Kuala Lumpur: Dewan Bahasa dan Pustaka.

Ito. (1978). Why did al-Raniri leave Aceh. Bidgragen Tot de-T'al.

Mohamad Nasrin Nasir. (2004). "Persian Influences in the Teachings of Hamzah Fansūrī”. Imtiyaz Yusuf (Ed.) Proceedings of the International Conference on Measuring the Effects of Iranian Mysticism upon Southeast Asian Mysticism. Bangkok: Iranian Cultural Center.

MSS4661, Pusat Manuskrip Melayu, Perpustakaan Negara Malaysia.

Voorhoeve, P. (1969). Notes on Some Manuscripts in the Library of the Dewan bahasa dan Pustaka. Bijdragen tot de Taal-en Volkenkunde, 125(3), 371373.

Sweeney, A. (1980). Authors and Audiences in Traditional Malay Literature. Monograph no.20, Center for South and Southeast Asia Studies. Berkeley: University of California.

Sweeney, A. (1990). The Journal of Asian Studies, 49(4), 1005-1006. doi: $10.2307 / 2058336$ 
MALAY LITERATURE VOLUME 33 NUMBER 1 JUNE 2020

Van Nieuwenhuijze (1945). Samsu'l-Dīn Van Pasai, Bijdrage tot de Kennis der Sumatraansche Mystiek (Sumbangan pada Ilmu oleh Seorang Sufi dari Sumatra). Leiden: E.J.Brill.

W. Saghir W.Abdullah. (2002). Al-Ma'rifah 1. Kuala Lumpur: Khazanah Fathaniyyah.

Received: 25 June 2019

Accepted: 26 May 2020 